\title{
Genetics of obesity and human energy metabolism
}

\author{
BY CLAUDE BOUCHARD, JEAN-PIERRE DESPRES \\ AND ANGELO TREMBLAY \\ Laboratoire des Sciences de l'Activité Physique, PEPS, Université Laval, Ste-Foy, Québec, \\ Canada, G1K $7 P 4$
}

Our understanding of the factors responsible for the individual differences in body fat content and the various components of energy expenditure is quite limited. We commonly recognize that there are individual differences within ethnic or racial groups living under given environmental and social conditions. Important correlates of these individual differences have been identified but they are not sufficient to draw a complete and integrated picture of all contributing elements. Our relative ignorance about the phenotypes, their assessment and all their affectors carries major implications for those interested in the genetics of body fat or obesity and energy metabolism.

One consequence of this situation has been the total reliance up to now on the top-down approach (Sing et al. 1988) in studying the genetics of obesity and energy metabolism (Fig. 1). This is analogous to the situation that prevailed also, up until recently, in the investigation of the genetics of blood lipids-lipoproteins, atherosclerosis, coronary heart disease and other common diseases (Sing et al. 1988). Thus, a large number of reports have dealt with the heritability of the body mass index (BMI) or skinfold measurements (for reviews see Bouchard \& Pérusse, 1988; Bouchard, 1989) and one study with body fat and fat-free mass derived from the underwater weighing assessment of body density (Bouchard et al. 1988a). In addition, three papers have been published on the familial resemblance or the heritability of resting metabolic rate (RMR; Fontaine et al. 1985; Bogardus et al. 1986; Bouchard et al. 1989), one on the heritability
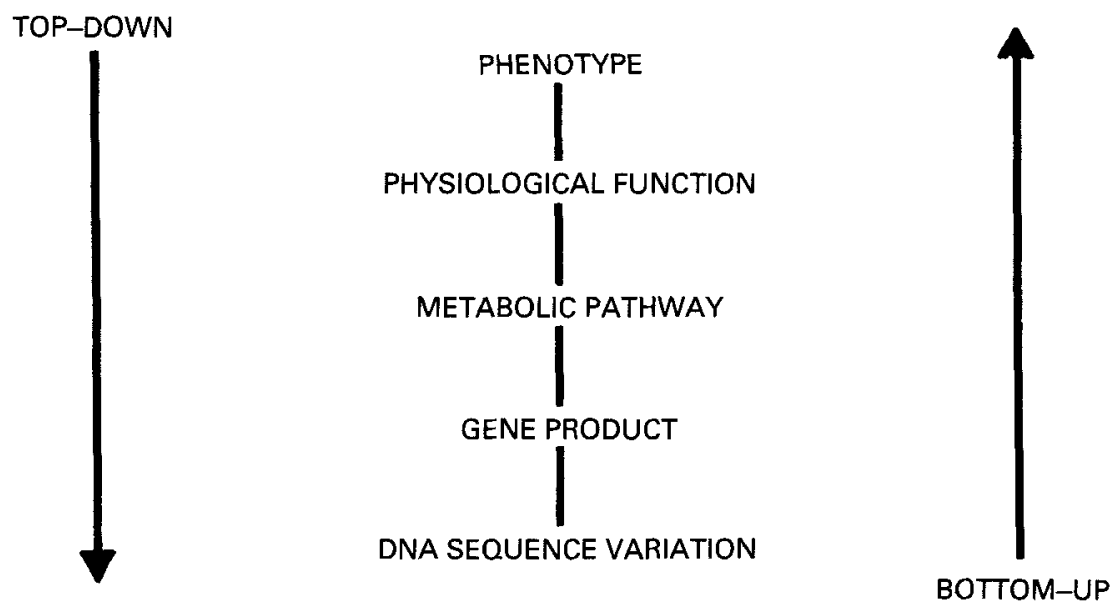

Fig. 1. A schematic illustration of two major research strategies pertaining to the study of the genetics of obesity and energy metabolism. The 'top-down' and 'bottom-up' concepts have been modified from Sing et al. (1988). 
of the thermic response to food and the energy cost of submaximal exercise (Bouchard et al. 1989), and one on the heritability of the level of physical activity (Pérusse $e t$ al. 1989). This is obviously a very limited body of knowledge that cannot be very helpful in defining the genetic mechanisms contributing to human variation in body fat content and energy metabolism.

We have extended these studies on the genetic epidemiology of body fat and energy expenditure phenotypes using an identical twin design (Bouchard et al. 1990b) in which both members of all pairs were exposed to the same standardized overfeeding treatment (Poehlman et al. 1986a,b; Tremblay et al. 1987; Bouchard et al. 1988b, 1990c). This experimental genetic approach, when used with a large sample size, properly defined and measured phenotypes and a variety of candidate physiological and metabolic pathways has the potential to contribute to the definition of the causal chain of events, to the assessment of the relative importance of genetic variation in the response to the treatment and to the identification of relevant candidate genes. It can, therefore, bring us closer to a bottom-up research strategy in our efforts to delineate the genetic mechanisms involved in variation of body fat and energy metabolism.

\section{HERITABILITY OF BODY FAT}

We will be concerned here only by commonly recognized indicators of weight status and obesity and not by regional fat distribution phenotypes. During the last 60 years or so, a large number of authors have reported that obese parents had a higher risk of having obese children than lean parents. This observation does not constitute a clear demonstration that the obesity of the offspring is determined by the so-called 'obesity' genes of the parents as both generations share not only genes but also the household milieu and many environmental conditions. The findings of these early studies were also not quite comparable as obesity was defined variously and methods of measurement were not identical across studies. Nonetheless, they clearly suggest that having an obese mother or one obese parent meant a greater risk of becoming obese (Bray, 1981; Mueller, 1983; Bouchard \& Tremblay, 1985; Price, 1987; Siervogel, 1988).

The literature on the topic of the genetics of the BMI as an indicator of weight status is confusing at times. There are dozens of reports that have dealt with one aspect or another of the problem and the additive genetic effect reported ranges from almost zero to values of about $90 \%$ of the age- and gender-adjusted phenotypic variance (Price, 1987; Bouchard \& Pérusse, 1988; Bouchard, 1989). Thus, one finds studies that have used information gathered on parents and their biological children, parents and their adopted children, regular brothers and sisters, siblings by adoption, and $\mathrm{DZ}$ and $\mathrm{MZ}$ twins. In general, these studies have drawn conclusions on the basis of only two or a few types of relatives, and the high values are generated from twin studies (Stunkard et al. 1986a). With few exceptions, they could not truly distinguish between the effects of the genes shared by descent from the household and environmental conditions shared by relatives living together. Recently, Stunkard et al. (1990) and MacDonald \& Stunkard (1990) reported on the BMI of various sets of $\mathrm{DZ}$ and $\mathrm{MZ}$ twins who had been reared together or apart. The estimates of heritability ranged from about $30 \%$ to $100 \%$, with a significant non-additive genetic component and, surprisingly, no shared childhood and familial environmental effects. In other words, having lived together in the same household did not influence the twin resemblance for the BMI. This finding is, of course, at odds with 


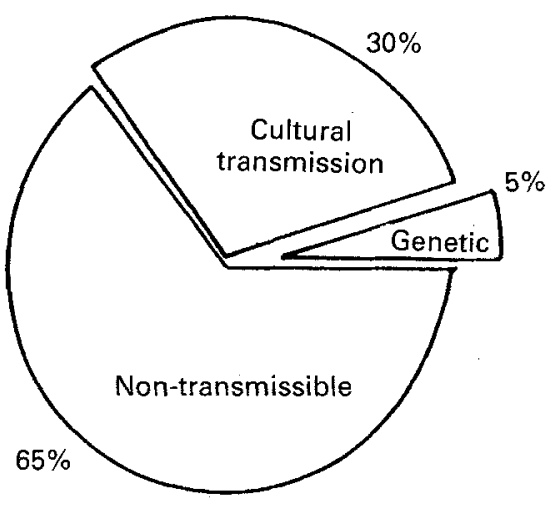

BMI and amount of subcutaneous fat

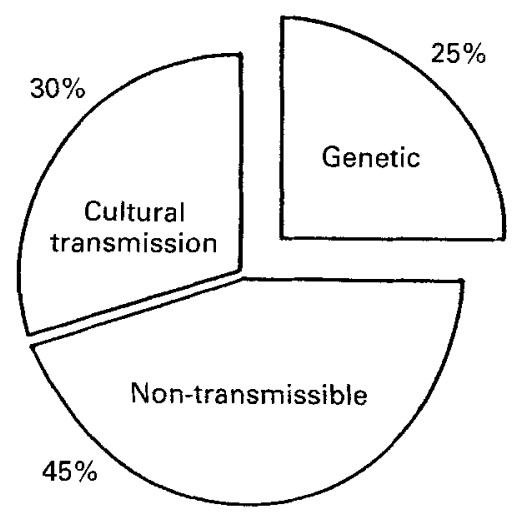

Percentage body fat and fat mass

Fig. 2. Total transmissible variance and its genetic component for body mass index (BMI), subcutaneous fat (sum of six skinfolds) and total body fat from underwater weighing. Modified from Bouchard et al. (1988b).

much of what we know about the familiality of body fat and about the effects of nutritional habits, habitual physical activity level and other lifestyle components on body-weight and body composition. As it is derived from values from twin studies alone, it should be interpreted with caution at this time.

Three adoption studies of BMI in singleton have been reported in recent years (Stunkard et al. 1986b; Price et al. 1987; Sorensen et al. 1989). They unanimously concluded that BMI values in the range of overweight and obesity are strongly influenced by genetic factors. We believe that the evidence to that effect is less than overwhelming. From our review of these studies, we find that the correlations between biological parents and offspring given for adoption is only about $0 \cdot 2$, while the correlation for foster parents and adopted children attains about $0 \cdot 1$. The difference between these two coefficients is of course compatible with a genetic effect but certainly not a strong one. Two recent studies have reported that there was evidence for a mixture of three components in the distribution of the BMI after control over the proper concomitants (Price \& Stunkard, 1989; Price et al. 1989). A dominant major gene effect on BMI was suggested in one study (Zonta et al. 1987). This cannot be interpreted easily and is likely to be a spurious result as the phenotype is variously determined by bone, muscle, adipose tissue and other tissues among individuals, with the contribution of each tissue changing with age and being different in both genders.

Based on a stratified sample of the Canadian population, BMI values were available on 18073 subjects living in 11884 different households (Pérusse et al. 1988). Based on these values, we were able to establish that the total transmission effect across generations for the age- and gender-adjusted BMI phenotypic variance reached about $35 \%$. In a separate data set, we have studied the relative importance of the genetic and the non-genetic (cultural) components of inheritance as well as the non-transmissible effect on the BMI phenotype after control over variations in age and gender (Bouchard et al. 1988a). The values were obtained in 1698 members of 409 families which included nine types of relatives by descent or adoption. Using the correlations computed for each of these kinds of relatives, we again reported a total transmissible variance across generations of about $35 \%$, but a genetic effect of only $5 \%$ (Fig. 2). The importance of the 
non-transmissible variance (about $65 \%$ ) may be partly caused by the fact that several tissues with their own pattern of transmission are contributing to the phenotype or because the BMI is indeed quite susceptible to lifestyle and environmental conditions. Taken as a whole these findings thus indicate that the BMI, an index of heaviness, is not characterized by a significant heritability component.

To the best of our knowledge, we have been alone in reporting on the genetic effect in fat mass and percent body fat measured with one of the commonly accepted direct methods for measuring body composition (Bouchard et al. 1988a). In this research, we had performed underwater weighing measurements of body density in a relatively large number of individuals belonging to nine different kinds of relatives. About half the variance after adjustment for age and gender, in fat mass or percentage body fat was associated with a transmissible effect and $25 \%$ of the variance was an additive genetic effect (Fig. 2). One must keep in mind that the study was conducted on a sample with only a small number of obese subjects. The genetic epidemiology of human obesity based on large samples of lean and obese subjects, with a valid assessment of body fat, is a task for the future. It should also be recognized that geneticists have not considered to a large extent maternal or paternal effects, X-linked or Y-linked effects, sex-limited effects or major gene effects in the human obesity phenotypes. In the same study based largely on normal weight and moderately overweight subjects, no specific maternal or paternal effects as well as no sex-limited effects could be detected for subcutaneous fat or total body fat (Bouchard et al. 1988a).

\section{RESTING METABOLIC RATES}

Information is available on four dimensions of human energy expenditure: habitual physical activity level, energy costs of submaximal exercise, resting metabolic rate and thermic effect of a meal and the evidence has been reviewed in two recent publications (Bouchard \& Tremblay, 1990; Bouchard et al. 1990a). A recent report has suggested that the habitual physical activity level, estimated from a $3 \mathrm{~d}$ activity record, was significantly influenced by undetermined genetic characteristics, the heritability coefficient reaching about $25-30 \%$ of the variance (Pérusse et al. 1989). These results were suggestive of inherited differences in the spontaneous level of activity.

The energy cost of submaximal exercise is an important element in the total energy balance equation as there are differences in oxygen uptake for a given power output. This issue was studied during submaximal cycle ergometer workloads in twenty-two pairs of $\mathrm{DZ}$ twins and thirty-one pairs of $\mathrm{MZ}$ twins. Evidence for a rather high (about $45 \%$ ) genetic effect was found at low power output but the genetic effect disappeared when the energy expenditure reached about six times the resting metabolic rate level (Bouchard et al. 1989).

Resting metabolic rate and the thermic response to food were studied in several sets of parent-child, and DZ and MZ twins (Fontaine et al. 1985; Bouchard et al. 1989). When resting metabolic rate was adjusted for age, gender and body mass variation as well as for differences in body composition, the heritability remained significant in all cases. Thus, for resting metabolic rate expressed on a per $\mathrm{kg}$ fat-free mass basis, the genetic effect reached about $40 \%$ of the total variance of the phenotype. These results are entirely compatible with those reported on Pima Indians (Bogardus et al. 1986) for resting metabolic rate measured in a room calorimeter. We have also studied the thermic 
Table 1. Correlations in relatives for the resting metabolic rate ( $R M R)$ and the thermic response (TEM) to a 4.2 MJ carbohydrate mealt (adapted from Bouchard et al. (1989))

\begin{tabular}{cccc}
\hline \hline & $\begin{array}{c}\text { Parent-child } \\
\text { (31 pairs) }\end{array}$ & $\begin{array}{c}\text { DZ twins } \\
\text { (21 pairs) }\end{array}$ & $\begin{array}{c}\text { MZ twins } \\
\text { (37 pairs) }\end{array}$ \\
\hline RMR: $\mathrm{kJ}$ & 0.29 & $0.50^{* *}$ & $0.79^{* * *}$ \\
$\mathrm{~kJ} / \mathrm{kg}$ fat-free mass & 0.21 & 0.30 & $0 \cdot 77^{* * * *}$ \\
TEM (\% of intake) & 0.30 & $0.35^{*}$ & $0 \cdot 52^{* * *}$ \\
\hline
\end{tabular}

$* P<0.05, * * P<0.01, * * * P<0.001$.

$\dagger$ Interclass correlation for parent-child; intraclass coefficient for the twins.

response to food after a 4.2 MJ carbohydrate meal (Bouchard et al. 1989). Our results show that the heritability reached at least $40 \%$ of the variation in the energy expended over the resting metabolic rate during $4 \mathrm{~h}$ after the test meal. Some of the correlations used for the computation of these heritability estimates are summarized in Table 1.

The same resting metabolic rate phenotypes were also studied in a $22 \mathrm{~d}$ overfeeding experiment with six pairs of identical twins (Poehlman et al. 1986b; Bouchard et al. $1988 \mathrm{~b}$ ). The within-pair resemblance in the changes of metabolic rates with overfeeding was also striking with $F$ ratios of between-pairs:within-pairs variances in response ranging from 2.5 to 5 and more. It is becoming increasingly clear that some of the genetic effects seen in fat mass are mediated by inherited differences in spontaneous activity level, energy cost of light submaximal exercise, resting metabolic rate and thermic effect of food. It is not known, however, whether these various genetic effects are generated by the same metabolic causes and what they are.

\section{RESPONSE TO OVERFEEDING}

The low to moderate additive genetic effect that we have reported thus far for obesity does not imply that genetic factors have little to do with variation in total body fat. It is generally recognized that there are some individuals prone to excessive accumulation of fat, for which losing weight represents a continuous battle, and others who seem relatively well protected against such a menace. We have recently tried to test whether such differences could be accounted for by genetic factors. In other words, we asked whether there were differences in the sensitivity of individuals to gain fat when chronically exposed to a positive energy balance and whether such differences were dependent or independent of the genotype. If the answer to both questions was affirmative then one would have to conclude that there was a significant genotypeenvironment interaction effect. The results from two experiments suggest that such an effect exists for total body fat (Poehlman et al. 1986a; Bouchard et al. 1988b, 1990c).

Thus, we have subjected both members of MZ twin pairs to a similar experimental treatment and compared intrapair (within genotype) and interpair (between genotypes) variances in the response. In one of these studies, twelve pairs of male $\mathrm{MZ}$ twins ate a $4 \cdot 2$ MJ (1000 kcal)/d energy surplus, $6 \mathrm{~d} / \mathrm{week}$, during a period of $100 \mathrm{~d}$ (Bouchard et al. 1990 c). Significant increases in body-weight and fat mass were observed after the period of overfeeding. Findings showed that there were considerable interindividual differences in the adaptation to excess energy and that the variation observed was not randomly 
Table 2. Body-energy gain in twenty-four adult males subjected to a $353 \mathrm{MJ}$ overfeeding treatment over $100 d^{*}$

\begin{tabular}{lc}
\hline Body mass changes & Energy equivalent \\
\hline Gain in fat mass: $5.4 \mathrm{~kg}$ & $210 \mathrm{MJ}$ \\
Gain in fat-free mass: $2 \cdot 7 \mathrm{~kg}$ & $12 \mathrm{MJ}$ \\
\hline
\end{tabular}

* For details of study, see Bouchard et al. (1990c).

distributed, as indicated by the significant within-pair resemblance in response. For instance, there were at least three times more variance in response between pairs than within pairs for the gains in body-weight and fat mass. These findings and others that we have reported earlier for the response to short-term overfeeding (Poehlman et al. 1986a; Bouchard et al. 1988b) demonstrate that some individuals are more at risk than others to gain fat when energy intake surplus is clamped at the same level for everyone and when all subjects are confined to a sedentary lifestyle. The within-identical-twin-pair response to the standardized energy surplus suggests that the amount of fat stored is likely influenced by the genotype.

The mean body mass gain for the twenty-four subjects of the $100 \mathrm{~d}$ overfeeding experiment was $8.1 \mathrm{~kg}$, of which $5.4 \mathrm{~kg}$ were fat mass and 2.7 were fat-free mass increases (Table 2). Assuming that the energy content of body fat is about $38.9 \mathrm{MJ} / \mathrm{kg}$ and that of fat-free tissue is $4.3 \mathrm{MJ} / \mathrm{kg}$, then a total of $222 \mathrm{MJ}$ were recovered on the average as body mass changes. This represents about $63 \%$ of the excess energy intake. There were, however, individual differences among the twenty-four subjects with respect to the amount of fat and fat-free tissues gained. Thus, while the mean gain of fat mass:fat-free mass ratio was $2: 1$, a ratio close to that reported previously (Forbes et al. 1986), it was $1: 2$ in one subject and it reached $4: 1$ and more in some other cases. The variations in the fat mass:fat-free mass ratio changes in response to overfeeding were correlated with the changes in body-weight and the coefficient reached $0.61 \quad(P<0 \cdot 01$; Bouchard et al. $1990 \mathrm{c}$ ). In other words, about $37 \%$ of the variation in weight gain as a result of exposure to long-term overfeeding was associated with this dimension of nutrient partitioning. Those who gained more fat relative to fat-free tissues were the high gainers for body mass while those who gained relatively more lean tissues were the low gainers.

If $63 \%$ of the extra energy consumed was accounted for by the changes in fat mass and fat-free mass, one is left with $131 \mathrm{MJ}$ to be accounted for. We measured the energy content of the faeces for several days before and after the overfeeding treatment in sixteen of the twenty-four subjects. There was no significant change in the amount of energy that was not absorbed during digestion. Thus, the remaining energy (about 131 MJ) must in all likelihood be associated with the obligatory costs of protein and fat tissues gained and with increases in resting metabolic rate, thermic effect of food, standard postures, moving the body around and fidgeting. One must also entertain the possibility that increases in energy expenditure for postures, bodily activities and fidgeting were present not only as a result of increases in body mass but perhaps also because of a shift in the daily pattern of activities towards a more energy-demanding profile even though subjects were kept under sedentary conditions.

The findings suggest at this point that when energy intake is clamped at the same level above baseline, two main classes of factors appear to be involved for a given genotype in 


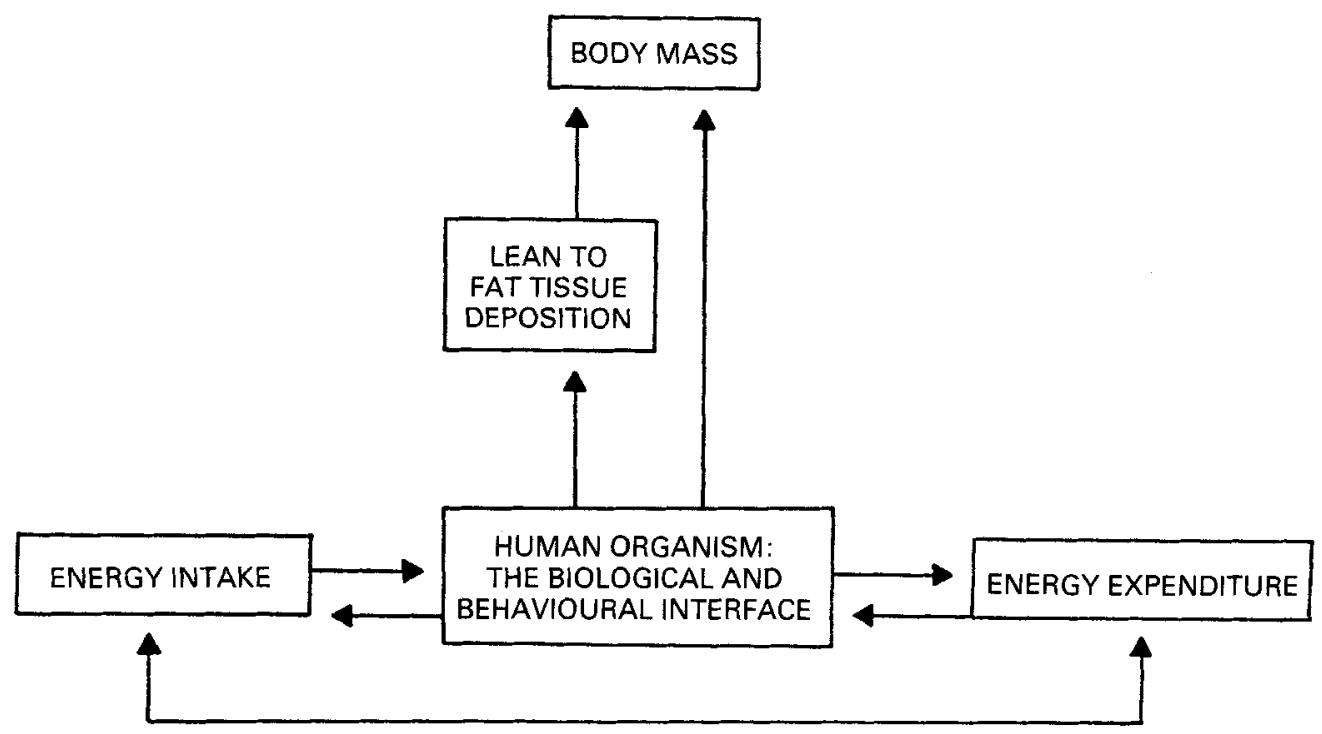

Fig. 3. A paradigm of the major affectors of body mass or body mass changes with variations in energy balance. It is a revision of the paradigm described by Bouchard (1987).

determining the changes in body mass. These are schematically illustrated in Fig. 3 which represents a modification of the paradigm that we presented several years ago (Bouchard, 1987). It would seem from the overfeeding study summarized here that nutrient partitioning (proneness to gain fat or fat-free tissues) is the single most important factor to explain the individuality in body-mass gain. Chances are that a substantial proportion of those prone or resistant to obesity find themselves in this vulnerable or desirable position because of inherited or acquired differences in nutrient partition affecting the outcome under a slightly overfed state and perhaps even under weight-stable and energy-balance conditions.

\section{CONCLUSIONS}

Several points should be emphasized in summarizing the role of biological inheritance in obesity and energy metabolism. From the findings reviewed here, we can conclude that the additive genetic effect for total or percentage body fat is about $25 \%$ of the age- and gender-adjusted phenotypic variance. The limited information available suggests that the genotype accounts for a significant fraction of the individual differences in resting metabolic rate, thermic effect of food and energy cost of light exercise even after age, gender, body mass and body composition are taken into account. Body-energy gains following overfeeding vary among individuals and variations in response are probably genotype-dependent. The proneness to gain fat or lean tissues when overfed appears to be a major determinant of the response to long-term overfeeding conditions.

The research reviewed in this paper was supported by the Medical Research Council of Canada, the Natural Sciences and Engineering Research Council of Canada and the National Institutes of Health of the USA. 


\section{REFERENCES}

Bogardus, C., Lillioja, E., Ravussin, E., Abbott, W., Zawadzki, J. K., Young, A., Knowler, W. C., Jacobowitz, R. \& Moll, P. (1986). Familial dependence of the resting metabolic rate. New England Journal of Medicine 315, 96-100.

Bouchard, C. (1987). Genetics of body fat, energy expenditure and adipose tissue metabolism. In Recent Advances in Obesity Research: $V$, pp. 16-25 [E. M. Berry, S. H. Blondheim, H. E. Eliahou and E. Shafrir, editors]. London: John Libbey.

Bouchard, C. (1989). Genetic factors in obesity. Medical Clinics of North America 73, 67-81.

Bouchard, C., Dériaz, O. \& Tremblay, A. (1990a). Génétique et métabolisme énergétique chez l'homme. (Genetics and energy metabolism in humans.) In Journées annuelles de diabétologie de l'Hôtel-Dieu, pp. 33-40 [M. Rathery, editor]. Paris: Flammarion.

Bouchard, C. \& Pérusse, L. (1988). Heredity and body fat. Annual Review of Nutrition 8, 259-277.

Bouchard, C., Pérusse, L. \& Leblanc, C. (1990b). A MZ twin study design that may provide indication about the genotype-environment interaction effect. Acta Geneticae Medicae Gemellologiae 39, 85-89.

Bouchard, C., Pérusse, L., Leblanc, C., Tremblay, A. \& Thériault, G. (1988a). Inheritance of the amount and distribution of human body fat. International Journal of Obesity 12, 205-215.

Bouchard, C. \& Tremblay, A. (1985). Genetics of body composition and fat distribution. In Human Body Composition and Fat Distribution, pp. 175-188 [N. G. Norgan, editor]. London: European Community Workshop on Nutrition.

Bouchard, C. \& Tremblay, A. (1990). Genetic effects in human energy expenditure components. International Journal of Obesity 14, Suppl. 1, 49-58.

Bouchard, C., Tremblay, A., Després, J. P., Nadeau, A., Lupien, P. J., Thériault, G., Dussault, J., Moorjani, S., Pinault, S. \& Fournier, G. $(1990 \mathrm{c})$. The response to long-term overfeeding in identical twins. New England Journal of Medicine 322, 1477-1482.

Bouchard, C., Tremblay, A., Després, J. P., Poehlman, E. T., Thériault, G., Nadeau, A., Lupien, P., Moorjani, S. \& Dussault, J. (1988b). Sensitivity to overfeeding: the Quebec experiment with identical twins. Progress in Food and Nutrition Science 12, 45-72.

Bouchard, C., Tremblay, A., Nadeau, A., Després, J. P., Thériault, G., Boulay, M. R., Lortie, G., Leblanc, C. \& Fournier, G. (1989). Genetic effect in resting and exercise metabolic rates. Metabolism 38, 364-370.

Bray, G. A. (1981). The inheritance of corpulence. In The Body Weight Regulatory System: Normal and Disturbed Mechanisms, pp. 185-195 [L. A. Cioffi, W. P. T. James and T. B. Van Itallie, editors]. New York: Raven Press.

Fontaine, E., Savard, R., Tremblay, A., Després, J. P., Poehlman, E. T. \& Bouchard, C. (1985). Resting metabolic rate in monozygotic and dizygotic twins. Acta Geneticae Medicae Gemellologiae 34, 41-47.

Forbes, G. B., Brown, M. R., Welle, S. L. \& Lipinski, B. A. (1986). Deliberate overfeeding in women and men: energy cost and composition of the weight gain. British Journal of Nutrition 56, 1-9.

MacDonald, A. \& Stunkard, A. (1990). Body mass indexes of British separated twins (Letter to the editor). New England Journal of Medicine 322, 1530.

Mueller, W. H. (1983). The genetics of human fatness. Yearbook of Physical Anthropology 26, 215-230.

Pérusse, L., Leblanc, C. \& Bouchard, C. (1988). Intergeneration transmission of physical fitness in the Canadian population. Canadian Journal of Sport Sciences 13, 8-14.

Pérusse, L., Tremblay, A., Leblanc, C. \& Bouchard, C. (1989). Genetic and environmental influences on level of habitual physical activity and exercise participation. American Journal of Epidemiology 129, 1012-1022.

Poehlman, E. T., Tremblay, A., Després, J. P., Fontaine, E., Pérusse, L., Thériault, G. \& Bouchard, C. (1986a). Genotype-controlled changes in body composition and fat morphology following overfeeding in twins. American Journal of Clinical Nutrition 43, 723-731.

Poehlman, E. T., Tremblay, A., Fontaine, E., Després, J. P., Nadeau, A., Dussault, J. \& Bouchard, C. (1986b). Genotype dependency of dietary induced thermogenesis: its relation with hormonal changes following overfeeding. Metabolism 35, 30-36.

Price, R. A. (1987). Genetics of human obesity. Annals of Behavioral Medicine 9, 9-14.

Price, R. A., Cadoret, R. J., Stunkard, A. J. \& Troughton, E. (1987). Genetic contributions to human fatness: an adoption study. American Joumal of Psychiatry 144, $1003-1008$.

Price, R. A., Sorensen, T. I. A. \& Stunkard, A. J. (1989). Component distribution of body mass index defining moderate and extreme overweight in Danish women and men. American Journal of Epidemiology 130, $193-201$.

Price, R. A. \& Stunkard, A. J. (1989). Commingling analysis of obesity in twins. Human Heredity 39, $121-135$. 
Siervogel, R. M. (1988). Genetic and familial factors in human obesity. In Childhood Obesity. A Biobehavioral Perspective, pp. 31-47 [N. A. Krasnegor, G. D. Grave and N. Kretchmer, editors]. Caldwell, New Jersey: Telford Press.

Sing, C. F., Boerwinkle, E., Moll, P. P. \& Templeton, A. R. (1980). Characterization of genes affecting quantitative traits in humans. In Proceedings of the Second International Conference on Quantitative Genetics, pp. 250-269 [B. S. Weir, E. J. Eisen, M. M. Goodman and G. Namkoong, editors]. Sunderland, Massachusetts: Sinauer Associates.

Sorensen, T. I. A., Price, R. A., Stunkard, A. J. \& Schulsinger, F. (1989). Genetics of obesity in adult adoptees and their biological siblings. British Medical Journal 298, 87-90.

Stunkard, A. J., Foch, T. T. \& Hrubec, Z. (1986a). A twin study of human obesity. Journal of the American Medical Association 256, 51-54.

Stunkard, A. J., Harris, J. R., Pedersen, N. L. \& McClearn, G. E. (1990). The body-mass index of twins who have been reared apart. New England Journal of Medicine 322, 1483-1487.

Stunkard, A. J., Sorensen, T. I. A., Hannis, C., Teasdale, T. W., Chakraborty, R., Schull, W. J. \& Schulsinger, F. (1986b). An adoption study of human obesity. New England Journal of Medicine 314, 193-198.

Tremblay, A., Poehlman, E. T., Nadeau, A., Dussault, J. \& Bouchard, C. (1987). Heredity and overfeedinginduced changes in submaximal exercise $\mathrm{VO}_{2}$. Journal of Applied Physiology 62, 539-544.

Zonta, L. A., Jayakar, S. D., Bosisio, M., Galante, A. \& Pennetti, V. (1987). Genetic analysis of human obesity in an Italian sample. Human Heredity 37, 129-139. 